\title{
The Use of Ultrasonic Feed Pre-Treatment to Reduce Membrane Fouling in Whey Ultrafiltration
}

Li Ling A. Koh ${ }^{\mathrm{a}, \mathrm{b}}$, Hanh Thi Hong Nguyen ${ }^{\mathrm{b}, \mathrm{c}}$, Jayani Chandrapala ${ }^{\mathrm{a}, \mathrm{d}}$, Bogdan Zisu ${ }^{\mathrm{e}}$, Muthupandian Ashokkumar ${ }^{\mathrm{a}}$ and Sandra E. Kentish ${ }^{\mathrm{b}, *}$

${ }^{\mathrm{a}}$ School of Chemistry, The University of Melbourne, VIC 3010 Australia

${ }^{b}$ Department of Chemical and Biomolecular Engineering, The University of Melbourne, VIC 3010 Australia

${ }^{c}$ Bio21 Molecular Science and Biotechnology Institute, The University of Melbourne, VIC, 3010 Australia

${ }^{\mathrm{d}}$ Current Address: College of Health and Biomedicine, Victoria University, VIC 3030, Australia

${ }^{\text {e }}$ Dairy Innovation Australia Limited, Werribee, VIC 3030, Australia

*Corresponding Author

Sandra E. Kentish

Department of Chemical and Biomolecular Engineering

The University of Melbourne

VIC 3010

Australia

Tel: $\quad+61383446682$

Fax: $\quad+61383444153$

Email: sandraek@unimelb.edu.au 


\begin{abstract}
The production of whey protein concentrate powders is often limited by the fouling of the ultrafiltration membranes and the low heat stability of the whey protein solutions. Ultrasonic treatment of whey solutions has previously been shown to break down protein aggregates and improve heat stability. This study investigates the use of ultrasound as a pre-treatment step to improve downstream ultrafiltration performance. Results show that sonication alone alleviated membrane fouling to a small extent. However, the use of ultrasound following heat exposure reduced membrane pore blockage and growth of the foulant cake greatly, relative to heat exposure in the absence of ultrasound. The extent of changes to pore blockage and cake growth was greater at higher solids concentration. In all cases, the protein concentration in the permeate remained unchanged. This work has the potential to reduce energy requirements in the ultrafiltration of whey as feed pre-treatment by both ultrasound and the combination of heat and ultrasound produced a lower viscosity feed solution.
\end{abstract}

\title{
Keywords
}

Ultrasound, ultrafiltration, whey protein, heat 


\section{Introduction}

The dairy industry relies heavily on membrane ultrafiltration (UF) for the concentration of whey, a by-product of cheese-making. Downstream, this concentrated whey is usually evaporated and spray dried to produce whey protein concentrate (WPC) powders of varying protein content ranging from 35 to $80 \%$. However, membrane fouling, which is a build-up of particles on the membrane surface and within its pores, reduces ultrafiltration performance, resulting in a sharp reduction in permeate flux and an increase in pressure drop across the membrane during filtration. Costly cleaning cycles and, in some cases, replacement of the membrane modules are required to restore the original flux, limiting the economic efficiency of the ultrafiltration operation.

Several modifications have been proposed to enhance membrane performance and reduce membrane fouling. Feed pre-treatment, installation of turbulence promoters and ultrasonic enhancements are examples of such modifications. In feed pre-treatment, the feed solution is treated using heat, $\mathrm{pH}$ adjustment, addition of complexing agents, precipitation or premicrofiltration. This alteration in feed properties stabilises or removes foulants upstream of filtration. Hickey and co-workers [1] observed an increase in permeate flux when the feed temperature and $\mathrm{pH}$ were increased prior to filtration. This was the result of the removal of calcium phosphate crystals, which would otherwise precipitate in the membrane pores, upon heating at higher $\mathrm{pH}$. However, a decrease in protein retention made this method infeasible [2].

The addition of turbulence promoters, such as vibratory shear-enhanced filtration and rotating disk modules, in a filtration unit enhances turbulence and back-transport and subsequently increases the shear rate near the membrane surface. Particle deposition is hence prevented and fouling is subsequently reduced. Akoum and co-workers [3, 4] have observed an increase in permeate flux in these systems when compared to a standard spiral wound membrane in the MF and UF of skim milk. However, the vibrating equipment is expensive and this limits membrane area and the potential for scale-up [2, 4].

The use of an ultrasonic field has been studied widely in membrane filtration systems for both flux enhancement during fouling [5-13] and to improve cleaning efficiency [14-17]. When an acoustic field is applied to a liquid, acoustic cavitation, a phenomenon in which bubbles present in the liquid medium grow and collapse due to pressure fluctuations caused by ultrasound waves, is generated. Acoustic cavitation generates shear forces, turbulence and micro-streaming, which 
can enhance membrane performance [18]. Muthukumaran et al. [19-21] found that during the ultrafiltration of whey, the permeate flux is enhanced significantly when a low-frequency, low power ultrasonic field is present. They speculated that at the membrane surface, the mass transfer coefficient within the concentration polarisation layer increases due to localised flow disturbances through bubble collapse and acoustic streaming. Microjets, which are also generated during cavitation, scour the surface, enhance turbulence and promote the backtransport of deposits to the bulk solution. The cake layer was also found to be less compressible and looser. More recently, Mirzaie et al. [22] obtained similar results in the microfiltration of milk where flux was enhanced by a factor of $490 \%$ with the use of ultrasound at $20 \mathrm{kHz}$. However, higher acoustic power levels and improper installation of the ultrasonic unit to the membrane can impact the structural integrity of the membrane [19, 20]. Large-scale filtration with ultrasonic enhancement may also be expensive due to high energy consumption [2].

Our recent work has shown that ultrasonic treatment of concentrated whey solutions independent of the filtration operation can reduce solution viscosity and protein aggregate size significantly [23]. The first aim of the present work is to determine whether such ultrasonic application upstream of ultrafiltration may be as effective as sonication during the UF process, as this would be considerably easier to implement.

Further, during evaporation of the whey solution downstream of filtration and in the use of the whey powders in downstream ingredient manufacture, the aqueous whey solution is often exposed to heat. Exposure to temperatures above $70{ }^{\circ} \mathrm{C}$ results in denaturation and aggregation of the whey proteins, often resulting in excessive thickening or gelling of the protein solution during processing and upon storage [24, 25]. This thickening limits the solids concentration that can be achieved upstream of spray drying and may also limit the application of the whey powders as dairy ingredients. Pre-treatment procedures, such as fore-warming and $\mathrm{pH}$ adjustment, have been developed to improve this heat stability. Of most relevance to this work is fore-warming: Deysher and co-workers [26] described the production of a heat stable condensed milk stream by the application of fore-warming as early as 1929 [24, 27-29]. However, this approach was found to be ineffective for spray-dried products as the resulting increases in viscosity that occur after heating restrict the ability to generate a dryer feed stream of high solids 
content. Furthermore, the aggregation that occurs during heating can result in later phase separation and protein precipitation.

Alternatively, we have used a combination of heat and ultrasound to improve heat stability [18]. When ultrasonic treatment is applied to a heated solution of denatured and aggregated proteins, there is a dramatic decrease in protein aggregate size and viscosity. It is speculated that these reductions are due to the disruption of hydrophobic interactions by shear forces that are generated during acoustic cavitation [30]. Upon further heating, the low viscosity is maintained, overcoming the problems of pre-treatment by forewarming and poor heat stability in the reconstituted powder [18]. With such a reduction in viscosity, it may be possible to process whey solutions to higher solids content in downstream evaporator units. The combination of heat and ultrasonic pre-treatment may be a promising approach in alleviating membrane fouling and enhancing spray dryer productivity while producing heat stable powders. This represents the second aim of this paper.

\section{Theory}

During UF at constant feed concentration, the flux decline curves can be analysed using a combined pore blockage and cake filtration model developed by Ho and Zydney [31]. These authors assume that the initial flux decline arises from the deposition of large aggregates, which block the membrane pores (Equation 1) [31].

$$
J_{\text {blocked }}=\frac{\Delta P}{\mu_{f}\left(R_{m}+R_{p}\right)}
$$

Equation 1

where $J_{\text {blocked }}$ is the flux through blocked pores $\left(\mathrm{m}^{3} / \mathrm{m}^{2} . \mathrm{s}\right), \Delta P$ is the transmembrane pressure (Pa), $\mu_{f}$ is the viscosity of the feed (Pa.s), $R_{m}$ is the clean membrane resistance and $R_{p}$ is the resistance of the protein deposit $\left(\mathrm{m}^{-1}\right)$. With time, there is increasing resistance for fluid to flow through the blocked regions as more particles settle on the membrane surface and contribute to the growth of a cake layer (Equation 2).

$$
\frac{d R_{p}}{d t}=f^{\prime} R^{\prime} J_{\text {blocked }} C_{b}
$$

Equation 2

where $f^{\prime}$ is the fractional amount of protein that contributes to deposit growth $(-), R^{\prime}$ is the specific resistance of the protein layer $(\mathrm{m} / \mathrm{kg})$ and $C_{b}$ is the bulk protein concentration $(\mathrm{g} / \mathrm{L})$. The volumetric flow rate through the open and blocked pores, $Q\left(\mathrm{~m}^{3} / \mathrm{s}\right)$, is finally determined as: 


$$
\begin{array}{cc}
Q=Q_{w}\left[\exp \left(-\frac{\alpha \Delta P C_{b}}{\mu_{f} R_{m}} t\right)+\left(\frac{R_{m}}{R_{m}+R_{p}}\right)\left(1-\exp \left(-\frac{\alpha \Delta P C_{b}}{\mu_{f} R_{m}} t\right)\right)\right] & \text { Equation } 3 \\
R_{p}=\left(R_{m}+R_{p 0}\right) \sqrt{1+\frac{2 f^{\prime} R^{\prime} \Delta P C_{b}}{\mu_{f}\left(R_{m}+R_{p 0}\right)^{2}} t}-R_{m} & \text { Equation } 4
\end{array}
$$

where $Q_{w}$ is the volumetric flux of pure water, $\alpha$ is the pore blockage parameter $\left(\mathrm{m}^{2} / \mathrm{kg}\right), t$ is the filtration time (s) and $R_{p 0}$ is the resistance of a single protein aggregate $\left(\mathrm{m}^{-1}\right)$. The first term within the brackets in Equation 3 represents the flow through the open pores and corresponds to the classical pore blockage model while the second term describes flow through the blocked pores. The permeate flux through the membrane is thus dependent on the pore blockage parameter $(\alpha)$, the initial resistance of the deposit $\left(R_{p 0}\right)$ and the cake growth rate (described by $\left.f^{\prime} R^{\prime}\right)$. The pore blockage parameter, also known as the rate of pore blockage, is equal to the membrane area blocked per unit mass of protein convected to the membrane surface and is an indication of the protein aggregate size [19]. The initial resistance of the protein deposit is a ratio of the initial resistance of the protein deposit to the membrane resistance. The cake growth factor represents the rate of increase of the protein layer resistance with time due to the growth of the protein cake layer.

This model was developed based on the microfiltration of bovine serum albumin. In further work, the authors have found the model to be in good agreement for the filtration of lysozyme, pepsin, immunoglobulin G and myoglobin [32] and the microfiltration of BSA-lysozyme and BSApepsin mixtures [33]. More recently, Muthukumaran et al. [19] obtained a good fit between the model and the experimental data in the ultrafiltration of WPC80 solution with and without in-situ ultrasound.

When the membrane operation is run at increasing feed concentration within a steady state, pressure independent filtration regime, a gel polarisation model can be used. This approach assumes that a concentration-polarised boundary layer exists above the precipitated cake or gel layer. Equation 5 is the classical equation used for the model.

$$
J C-J C_{p}=-D\left(\frac{d C}{d x}\right)
$$

Equation 5

where $C$ is the protein concentration within the concentration polarisation layer $\left(\mathrm{kg} / \mathrm{m}^{3}\right), C_{p}$ is the protein concentration in the permeate $\left(\mathrm{kg} / \mathrm{m}^{3}\right)$ and $D$ is the diffusion coefficient of the protein 
(m). Integrating Equation 5 across the concentration polarisation boundary layer gives the permeate flux:

$$
J=k_{C P} \ln \left[\frac{C_{g}-C_{p}}{C_{b}-C_{p}}\right]
$$

where $k_{C P}$ is the mass transfer coefficient due to concentration polarisation $(\mathrm{m} / \mathrm{s})$ and $C_{g}$ is the gel concentration $(\mathrm{g} / \mathrm{L})$. Assuming that total rejection of the solute is achieved at the membrane surface, $C_{p}=0$ and Equation 6 becomes:

$$
J=k_{C P} \ln \left(\frac{C_{g}}{C_{b}}\right)
$$

A plot of permeate flux against the natural logarithmic of protein concentration gives the mass transfer coefficient and gel concentration of the solute. A major disadvantage of this model is its inability to account for the change in feed properties, such as viscosity and density, as the concentration changes [34].

\section{Materials and Methods}

\subsection{Materials}

Whey protein concentrate (WPC80) powder containing 81.5\% protein, 10.4\% lactose and 4.4\% fat was provided by Warrnambool Cheese and Butter Factory (Allansford, Victoria, Australia). Fresh whey was also provided from this factory and contained $0.95 \mathrm{wt} \%$ protein, $5.3 \mathrm{wt} \%$ lactose $0.34 \mathrm{wt} \%$ fat and $0.58 \mathrm{wt} \%$ ash. Bradford reagent (Sigma-Aldrich, New South Wales, Australia), bovine serum albumin (BSA, Sigma-Aldrich, Fraction V, $\geq 96 \%$ ) and fast green FCF (SigmaAldrich) were used as supplied.

A flat-sheet UF membrane (K-131, Koch Membrane Systems, Massachusetts, USA) with a nominal molecular weight cut-off of $10 \mathrm{kDa}$ was used. This material consists of a semipermeable polyethersulfone (PES) layer on a polyolefin backing material.

\subsection{WPC80 Reconstitution and Pre-Treatment}

A full experiment involved WPC80 reconstitution, pre-treatment and filtration. In all experiments, the required amount of WPC80 was reconstituted in deionised water at ambient temperature $\left(22^{\circ} \mathrm{C}\right)$. After powder dissolution, the solution was left to stir for an hour and then stored overnight in the refrigerator at $4{ }^{\circ} \mathrm{C}$. When feed pre-treatment was not required, the 
solution remained in the refrigerator on the second day before filtration on Day 3; filtration was not performed on Day 2 so as to maintain an identical age of all WPC80 solutions before filtration.

For heat pre-treatment (PreH), reconstituted WPC80 solution was pumped at $80 \mathrm{ml} / \mathrm{min}$ through a set of coils immersed in a water bath at $80{ }^{\circ} \mathrm{C}$, with a residence time of 3 min $20 \mathrm{~s}$. The solution was collected in a separate container, which was placed in an ice bath for rapid cooling to approximately $20^{\circ} \mathrm{C}$.

A $20 \mathrm{kHz}, 400 \mathrm{~W}$ S-450D generator and 13 mm diameter horn transducer (Branson Ultrasonics, Connecticut, USA) was used for sonication (US) at an amplitude of $30 \%$ with an in-line continuous flow cell (Branson Part No. 100-146-171). A Masterflex peristaltic pump (John Morris, New South Wales, Australia) was used to pump liquid through the cell at $60 \mathrm{ml} / \mathrm{min}$. The cell had an external cooling jacket for circulation of cold water to ensure that the WPC80 solution was kept at $5 \pm 2{ }^{\circ} \mathrm{C}$ during the entire pre-treatment process. A diagram of this experimental setup is provided as Figure 1.

A single-phase energy cost meter (Arlec, Victoria, Australia) was used to measure the power drawn from the power supply for the sonicator and this was found to be $101 \mathrm{~W}$. The power delivered as ultrasonic energy, or calorimetric power, was measured as $31 \mathrm{~W}$. This value was determined by measuring the temperature change in water, in the absence of a cooling jacket, using the following equation [35, 36]:

$$
P=C_{p w} M\left(\frac{\Delta T}{t}\right) \quad \text { Equation } 3.1
$$

where $C_{p w}$ is the heat capacity of water $\left(=4.18 \times 10^{3} \mathrm{~J} / \mathrm{kg} . \mathrm{K}\right), M$ is the mass of water used (kg), $\Delta T$ is the change in temperature $(\mathrm{K})$ and $t$ is the duration of sonication (s).

The resulting energy density delivered to the solution was $31 \mathrm{~J} / \mathrm{ml}$ (calculated as the product of the calorimetric power and the inverse of the flow rate through the sonicator). This energy density was chosen as it has been shown to be adequate in our prior work to disrupt whey protein aggregates and reduce the viscosity of whey protein concentrates [18, 37]. The use of higher energy densities is unlikely to be economic in a commercial setting. 


\subsection{Filtration}

A Micropump GC-M35 positive displacement pump (IDEX Corporation, Washington, USA) was used to circulate the feed WPC80 solution to the membrane cell through a set of coils which were immersed into a Ratek RC4 refrigerated bath (Ratek Instruments, Victoria, Australia) to maintain the feed temperature at $5{ }^{\circ} \mathrm{C}$ (Figure 2). The flow rate of the feed solution was controlled by a Eurotherm 650 variable speed pump drive (Invensys Eurotherm, Virginia, USA) while a GO BP-3 back-pressure regulator (Go Regulators, South Carolina, USA) was installed on the retentate line to control the transmembrane pressure. The retentate was returned to the feed tank while permeate was collected in a beaker placed on an O’Haus PA2102 mass balance (O’Haus, New Jersey, USA). In constant concentration mode, the permeate was also returned to the feed tank at regular intervals.

The Sepa CF II membrane cell (GE Osmonics, Minnesota, USA) consisted of a stainless steel cell body and an aluminium cell holder. A diamond feed spacer, shim and permeate carrier were used with thicknesses of 1.2, 0.13 and $0.35 \mathrm{~mm}$ respectively.

At the start of each filtration run, deionised water was circulated through the system at $3.5 \mathrm{~L} / \mathrm{min}$ and transmembrane pressure (TMP) of 2.0 bar for 30 mins to obtain a stable flow field. The water flux was then recorded for the next 30 mins.

After water filtration, the membrane was fouled with the feed solution for $4 \mathrm{~h}$ at $3.5 \mathrm{~L} / \mathrm{min}$ and TMP of 2.0 bar in constant concentration mode. The change in absolute permeate flux with time for different feed solutions were analysed using the combined pore blockage and cake filtration model (Equation 3 and Equation 4). The best fit values of the three model parameters (pore blockage parameter, initial resistance of the protein deposit and cake growth factor) were determined by minimising the sum of the squared residuals between the above experimental permeate flux data and the model calculations for each of the feed solutions separately. The feed viscosity used in the model calculations was the value determined experimentally for each solution.

The gel concentration of the system was determined using Equation 7 to compare the steady state flux values of feed solutions of differing concentration. A line of best fit with the smallest sum of 
the squared errors was used in the determination of the gel concentration from flux data obtained by averaging the last 10 recorded values, which corresponded to the last 10 mins of fouling during each $4 \mathrm{~h}$ run.

To determine the extent of reversible fouling, deionised water was circulated through the system at $3.5 \mathrm{~L} / \mathrm{min}$ and TMP of $2.0 \mathrm{bar}$ for 30 mins after fouling. The irreversible fouling layer was then removed using Reflux R400 (Orica Australia), an acidic cleaner, at pH 2.0 to 2.2 and Reflux B615 (Orica Australia), an alkaline cleaner, at pH 10.8 to 11.0. Deionised water was circulated in between the acidic and alkaline cleaning steps and at the end of cleaning. All steps were performed at $5 \mathrm{~L} / \mathrm{min}, 2.0$ bar and at ambient temperature except for the acidic and alkaline cleaning steps, which were performed at $50{ }^{\circ} \mathrm{C}$. After cleaning, a pure water flux was recorded for the next 30 mins to determine the overall cleaning efficiency.

\subsection{Analytical Methods}

The size distribution of protein aggregates was determined using a Malvern Mastersizer 2000 laser diffraction system (Malvern Instruments, Malvern, UK). Refractive indices of 1.58 for the whey protein agglomerates and 1.33 for the dispersant, which was water, with an absorption coefficient of 0.001 were used [37]. Samples were shaken by hand before dispersion into water to obtain an obscuration of $10 \%$. Mie theory [38] was used to analyse the data, taken as the average of three measurements and expressed as the volume-weighted average particle size, $\mathrm{D}[4,3]$.

To measure viscosity, a $40 \mathrm{~mm}$ parallel plate geometry with a gap of $1 \mathrm{~mm}$ was used on an ARG2 Rheometer (TA Instruments, New Castle, USA). A conditioning step was first performed to equilibrate the sample to $25^{\circ} \mathrm{C}$ followed by a continuous ramp step to obtain the viscosity profile at increasing shear rates from 10 to $200 \mathrm{~s}^{-1}$.

The total protein concentration in the feed, retentate and permeate streams of each filtration run was measured using Bradford reagent according to the instructions provided by the manufacturer. $1.5 \mathrm{ml}$ of Bradford reagent was added to $100 \mu \mathrm{L}$ of sample and vortexed before leaving to stand for $20 \mathrm{~min}$. The absorbance values of the samples were then measured at $595 \mathrm{~nm}$ using a Carey 50 Bio UV-visible spectrophotometer (Varian, Palo Alto, USA) and compared against a linear calibration curve created using solutions containing various concentrations of BSA. 


\subsection{Imaging Techniques}

Protein aggregate size and distribution were investigated using confocal laser scanning microscopy (CLSM). To $1 \mathrm{ml}$ of sample, $10 \mu \mathrm{L}$ of fast green FCF was added for staining of protein. The solution was left undisturbed for 15 to 30 mins. After staining, 5 to $7 \mu \mathrm{L}$ of fluorescently-labelled solution was placed on the slide, covered with a glass coverslip and secured with nail polish. The sample was then inverted and viewed using an oil immersion lens and an inverted Leica TCS SP2 CLSM. Fast green FCF was excited at $633 \mathrm{~nm}$ and the emission filter was set at 600 to $710 \mathrm{~nm}$.

\section{Results and Discussion}

\subsection{Effect of ultrasound on feed solution properties}

The CLSM images in Figure 3(a) show that the average particle size of the whey protein aggregates of a $5 \mathrm{wt} \%$ WPC80 solution is less than $1 \mu \mathrm{m}$. However, when using a Mastersizer to analyse the volume-weighted average particle size, a bimodal distribution is obtained with a large peak in the range 10-100 $\mu \mathrm{m}$, signifying a small number of large aggregates (Figure 4). The absence of large aggregates of this size in CLSM imaging may be due to the overestimation of particle size by the Mastersizer and the underestimation of the particle size by the CLSM or the incomplete staining of larger aggregates or fat globules. With sonication (US), the aggregate size is reduced (Figure 3(b)). The large peak in the Mastersizer particle size distribution disappears as the large particles are reduced to less than $1 \mu \mathrm{m}$, giving a volume-weighted average particle size, $\mathrm{D}[4,3]$ of $0.19 \mu \mathrm{m}$ (Figure 4 and Table 1). A slight decrease in viscosity is also observed (Table 2).

Upon heat treatment of the native solution (PreH), there is an increase in particle size of the whey protein aggregates and a corresponding increase in the viscosity of the WPC80 solution (Figure 4, Table 1 and Table 2). At temperatures above the denaturation temperature, the proteins partially unfold and expose hydrophobic groups that were previously buried inside the macromolecules. These partially unfolded proteins interact with each other by calcium bridging and hydrophobic interactions to form protein aggregates [39-42]. The CLSM image (Figure 3(c)) shows that protein aggregation is random with no fixed shape and size. 
When the pre-heated sample is subjected to sonication (PreH+US), a sharp decrease in both particle size and viscosity is observed. Indeed, the average particle size and viscosity of the PreH+US samples are generally comparable to, or lower than, the original native values Figure 3(d), Table 1 and Table 2). This may be due to the disruption of hydrophobic interactions by ultrasound-induced shear forces [18, 30]. Upon further heating, the reduced particle size and viscosity of the sample is preserved, signifying the heat stability of the sample after sonication (Figure 3(e), Figure 4 and Table 2).

As the solids concentration increases, the average particle size and viscosity of all samples increase as a higher protein concentration allows greater opportunity for the proteins to aggregate. Iametti et al. [43] studied the effect of protein concentration, at neutral $\mathrm{pH}$, on the thermal denaturation and aggregation of $\beta$-lactoglobulin ( $\beta$-LG), a major constituent of whey proteins, and concluded that the concentration does not affect protein unfolding but greatly affects the extent of aggregation. At high protein concentrations, the formation of high molecular weight aggregates is favoured over trimers and tetramers and their relative composition increased with increasing concentration. Both Elofsson et al. [44] and Qi et al. [45] observed similar results that showed increasing aggregation with high solids concentrations. Due to the lack of free sulphydryl groups, $\alpha$-lactalbumin ( $\alpha$-LA), which is the second most abundant whey protein, does not polymerise itself when heated. However, in the presence of $\beta$-LG or other proteins containing free sulphydryl groups, interactions occur between these proteins and $\alpha$-LA. The rate and extent of aggregation of $\alpha$-LA is hence dependent on the concentration of free sulphydryl groups in the system [46]. In addition, Havea et al. [42] showed that the extent of aggregation in heat-treated WPC was affected by its initial concentration. With $\beta$-LG being a major constituent of WPC80, it can be concluded that in our system, the increasing concentration of WPC80 and subsequently $\beta$-LG led to greater formation of high molecular weight $\beta$-LG aggregates and $\beta$-LG- $\alpha$-LA complexes upon heating.

\subsection{Effect of ultrasonic pre-treatment on membrane fouling}

With $5 \mathrm{wt} \%$ WPC80 solutions there is no change in the ultrafiltration flux decline pattern between the native and sonicated solutions within experimental error and the percentage flux reductions in both feeds are similar (Figure 5). Conversely, at a higher solids concentration of 10 $\mathrm{wt} \%$, there is a small but significant difference in the flux reduction for the two feeds. A steeper 
initial flux decline is clearly observed in the native sample. There was no change in the protein concentration in the permeate in either case.

The solid curves in Figure 5 represent the model fits to the Ho and Zydney model [31] and these show good agreement with the experimental data over the entire filtration period. At short times, the rapid flux decline, which is exponential with time, is dominated by pore blockage. At longer filtration times, the gradual flux decline is dominated by the growth of the cake layer. The best fit values of the model parameters are shown in Figure 6.

The pore blockage parameters obtained for native 5 and $10 \mathrm{wt} \%$ WPC80 samples are 2.0 and $2.9 \mathrm{~m}^{2} / \mathrm{kg}$ respectively. These values are slightly lower than that reported in prior work with WPC80 solutions (2.5 to $3.4 \mathrm{~m}^{2} / \mathrm{kg}$ ) [19]. This may be the result of batch-to-batch variability in the WPC powder or it may indicate a more thorough reconstitution of the original powder. As a comparison, Ho and Zydney [31] obtained a value of $2.9 \pm 2.6 \mathrm{~m}^{2} / \mathrm{kg}$ for BSA.

Upon sonication, the pore blockage parameters for both solids concentration reduce slightly (Figure 6). These results are consistent with those when ultrasonics was applied directly to the UF module where reduced pore blockage was also observed [19]. The reduction in pore blockage can be related directly to the reduction in protein aggregate size, giving rise to a gentler flux decline at the start of the filtration when compared to that obtained for the native feed.

The initial resistance of the protein deposits for native $5 \mathrm{wt} \%$ WPC80 feed is $1.22 \times 10^{12} \mathrm{~m}^{-1}$. Extrapolation of the data obtained back to lower values of TMP indicates consistent results to those presented by Ho and Zydney for BSA [31] but considerably lower than those obtained by Muthukumaran et al. for WPC80 [19]. The resistance increases slightly upon sonication for the $5 \%$ case. Conversely, for a $10 \mathrm{wt} \%$ feed, a decline is observed.

The cake growth factor for the $10 \mathrm{wt} \%$ feed decreases with sonication (Figure 6). This is consistent with prior work when US was applied directly to the membrane device, where ultrasound lowers the compressibility of the growing cake [19]. However, the absolute values of this factor are considerably lower than that previously reported (1.7 x $10^{13} \mathrm{~m} / \mathrm{kg}$ at 2.25 bar [19]) and the reason for this discrepancy is unclear. It is worth noting that in both feed types, the protein concentration in the permeate was low at $0.05 \mathrm{wt} \%$. 
Overall, pre-treating the feed through sonication alone produced small but significant changes to membrane fouling. At higher solids concentration, sonication delays the effects of fouling to a small extent by reducing the rate of pore blockage and cake growth. The inability of sonication to reduce fouling more dramatically may be due to the small aggregate size and low viscosity of the native WPC80.

\subsection{Effect of heat and ultrasonic pre-treatment on membrane fouling}

For heat-treated solutions, there was a clearer distinction between the flux data for the sonicated and unsonicated feeds. A steeper slope was observed at the start of the run of the pre-heated only feed, signifying greater blockage of pores, which was a result of larger, denser aggregates. This led to substantial differences in the steady state flux (Table 4). The differences were reflected in much greater values of the pore blockage parameter (Figure 7). Further, the pore blockage parameters for all heat-treated feeds increased relative to the native feeds and with increasing solids concentration. In the PreH feeds, this increase in pore blockage parameter is due to the increase in the number of large aggregates with increasing solids concentration, resulting in the observed greater flux reduction. On the other hand, the aggregates in the PreH+US feeds were partially broken down by sonication, leading to lower pore blockage values.

In most cases, the initial resistance of the deposit of the PreH feed, however, was slightly smaller when compared to the feed that was sonicated after the pre-heat step (Figure 7). The exception was for the 12 wt\% feed, where large errors were obtained. This may have been due to insufficient stirring in the feed tank during this run, so that the returning permeate and retentate were not thoroughly integrated, leading to inconsistencies in the composition of the feed passing through the membrane filtration unit.

The cake growth factors of the heat-treated only feeds increase with solids concentration, signifying the formation of denser cake layers and a higher resistance to flow (Figure 7). Sonication reduces this cake growth factor due to a lower fraction of protein contributing to the growth of the deposit. Although the cake growth factors remain lower at all solids concentrations of the PreH+US feeds, an increase in cake growth with concentration is still observed.

Even though higher flux and lower membrane fouling was achieved for the PreH+US feed, the protein concentration in the permeate remained unchanged at $0.07 \mathrm{wt} \%$. In addition, the lower 
viscosity of the PreH+US feed (Table 2) is likely to lead to lower crossflow pressure drops and hence, improved energy efficiency for ultrafiltration. However, it is also important to note that the absolute permeate flux of the PreH and PreH+US solutions were still lower than that of the non-heated feeds (Table 3).

It is also worth noting that the steady state flux obtained for a $15 \mathrm{wt} \% \mathrm{PreH}+\mathrm{US}$ feed was higher than that of a pre-heated $12 \mathrm{wt} \%$ feed without sonication (Table 3). This is the result of a smaller particle size and a lower viscosity feed. Hence, with the use of ultrasound, it is possible to process a heat-treated dairy whey solution at higher solids concentration with higher absolute flux, significantly lower fouling levels and similar protein concentration in the permeate while maintaining heat stability of the solution for downstream processing.

Plots of the steady state flux data against the natural logarithm of feed concentration, as shown in Figure 8, provide a linear relationship; consistent with the gel polarisation model as represented by Equation 7. The gradient of these linear plots give a mass transfer coefficient of $2.44 \times 10^{-6}$ $\mathrm{m} / \mathrm{s}$ for all systems. The gel concentrations, which are determined from the vertical intercepts of the plots, are 210, 290 and $620 \mathrm{~g} / \mathrm{L}$, or 20.6, 26.5 and $44 \mathrm{wt} \%$ for the PreH, PreH+US and native feeds respectively. Muthukumaran [47] obtained a mass transfer coefficient of $1.5 \times 10^{-6} \mathrm{~m} / \mathrm{s}$ and a gel concentration of $45 \mathrm{wt} \%$ for a native whey protein solution. A higher mass transfer coefficient is obtained in this study due to a higher cross-flow velocity used when compared to the Muthukumaran work [47]. Due to the denaturation of the proteins as a result of heating, which allows the proteins to 'gel' at lower concentrations, lower gel concentrations are obtained for the heat-treated feeds. A larger gel concentration is observed in the PreH+US system when compared to the PreH feed. This shows that sonication delays the 'gelling' of proteins and coincides with the results obtained using the combined pore blockage and cake filtration model [31], where the PreH+US systems have lower pore blockage and slower cake growth.

\subsection{Effect of heat and ultrasonic pre-treatment on reversible fouling and cleaning}

Reversible fouling is defined as the deposits which are easily removed by rinsing water through the UF membrane system and can be determined through the flux recovered by water flushing. Irreversible fouling, on the other hand, refers to the fouling layer that can only be removed 
through chemical cleaning and is calculated using the flux obtained after cleaning relative to the original water flux obtained at the start of the filtration run.

The extent of reversible and irreversible fouling was similar for both native and sonicated feed (Table 4). This was mainly due to the small differences between the two samples in both particle size and viscosity. The flux was fully recovered after chemical cleaning in these cases with the value of $103 \%$ recorded for the sonicated feed. The value above $100 \%$ reflects the presence of residual surfactants, which are known to enhance the water flux. When the membrane is soaked in deionised water between runs, the absolute water flux in the next run falls back to the original value, signifying the removal of these surfactants during storage.

For heat-treated feed filtration, the flux recovered by water flushing (reversible fouling) reduced considerably, reflecting the denaturation of the proteins. Sonication increased the proportion of reversible fouling that can be removed by this approach but was unable to reach the level observed with the native feed solution.

After chemical cleaning, $100 \%$ flux recovery for both heat-treated solutions was unachievable. This may be due to the inability of the cleaning solutions to break down and dissolve larger aggregates. As the PreH+US feed has a smaller proportion of large aggregates and a high proportion of foulants are removed by water flushing, the flux obtained after cleaning is higher than that of the PreH feed.

\subsection{Fresh Whey}

The effect of ultrasonic pre-treatment on the UF of fresh whey was also investigated (Figure 9). The permeate flux for the native fresh whey solution was significantly higher than that of native 5 wt\% WPC80 solution. The higher flux is due to the lower protein level (approximately $0.95 \mathrm{wt} \%$ ) in this fresh whey. Although the protein concentration in fresh whey is lower, the UF of fresh whey suffers a greater flux decline. This may be attributed to the presence of residual fat and the native conformation of proteins, both of which foul the UF system more quickly. The presence of lactose and salts in the whey solution also increases the osmotic pressure at the membrane surface and may lead to calcium scaling. Hayes et al. [49] studied the UF of whey proteins and observed a lower flux decline when the whey salts are removed. In a similar study, Muthukumaran [47] obtained a higher flux decline for whey than WPC for the same protein concentration. However, similar to WPC80 
feeds, the difference in flux decline between the native and sonicated whey feeds is small but significant (Figure 9). Protein, lactose and ash retention for the two cases are identical within experimental error (data not shown).

Unlike the WPC80 feeds, the pore blockage of the sonicated fresh whey feed was significantly higher than the native feed (Table 5). In addition to smaller whey protein aggregates, the reduction in the size of residual fat globules, present in fresh whey, may have blocked the pores more readily; the fat content in fresh whey and $5 \mathrm{wt} \%$ WPC80 are $0.34 \mathrm{wt} \%$ fat and $0.22 \mathrm{wt} \%$ respectively. A lower initial protein deposit resistance was also observed for the sonicated whey feed (Table 5). Consistent with the work on WPC80, sonicated whey feed provided a substantially lower cake growth factor when compared to the native feed, signifying the low compressibility of the growing cake. However, the cake growth factors of the fresh whey feed was significantly greater than that of the 5 wt\% WPC80 feeds. This indicates the importance of residual fat globules and whey salts on fouling.

\section{Conclusion}

Pre-treatment of both a WPC80 solution and fresh whey through sonication alone had a small but significant effect on membrane fouling, as indicated by the flux reductions, pore blockage parameters and cake growth factors obtained in both native and sonicated feeds. The relatively minor nature of the changes may reflect the low solids concentrations used in these experiments and the use of more concentrated protein solutions might lead to more positive results.

Conversely, a larger decline in pore blockage and cake growth was observed when a pre-heated whey protein solution was sonicated, providing a more pronounced effect for the combined use of heat and ultrasound as a feed pre-treatment technique. With increasing solids concentration, both pore blockage and cake growth grew for all heat-treated feeds although these two parameters remained low for the PreH+US feeds. In addition, no change to the protein concentration in the permeate was observed in all systems. Coinciding with the results obtained with the combined pore blockage and cake filtration mode, the gel concentration of the PreH+US feed was found to be slightly higher than that of the PreH feed, indicating that sonication delays the 'gelling' of the protein. However, the gel concentration remained well below that of the native protein. 
This study has thus shown that feed pre-treatment through heat and ultrasound can provide a viable approach to the production of concentrates for use in heat stable powders through ultrafiltration. However, due to the low absolute flux arising from pre-heat treatment, even in combination with sonication, it may be more feasible to concentrate whey in its native form in the early stages of filtration prior to the combined use of heat and ultrasonic treatments. In this manner, the flux and hence, productivity, will not be compromised at the expense of heat stability.

Both feed pre-treatment methods, ultrasound and the combination of heat and ultrasound, have the potential to reduce energy requirements in the UF of whey due to the production of a lower viscosity feed solution, which will reduce crossflow pressure drops. However, this energy saving must be offset against the energy demand of the sonication itself. The present results would suggest that the net benefit of sonication, which also includes the ability to operate at higher production rates due to increased flux, will only be positive at high solids concentrations.

\section{Acknowledgements}

This work was supported by The Australian Research Council (ARC-LP scheme), Dairy Innovation Australia and the Particulate Fluids Processing Centre.

\section{References}

[1] M.W. Hickey, R.D. Hill, B.R. Smith, Investigations into the ultrafiltration and reverse osmosis of wheys 1 . The effects of certain pretreatments, New Zealand Journal of Dairy Science and Technology, 15 (1980) 109-121.

[2] G. Brans, C.G.P.H. Schroën, R.G.M. van der Sman, R.M. Boom, Membrane fractionation of milk: state of the art and challenges, Journal of Membrane Science, 243 (2004) 263-272.

[3] O. Al-Akoum, L.H. Ding, M.Y. Jaffrin, Microfiltration and ultrafiltration of UHT skim milk with a vibrating membrane module, Separation and Purification Technology, 28 (2002) 219-234.

[4] O. Akoum, M.Y. Jaffrin, L.-H. Ding, Concentration of total milk proteins by high shear ultrafiltration in a vibrating membrane module, Journal of Membrane Science, 247 (2005) 211-220.

[5] M. Cai, S. Zhao, H. Liang, Mechanisms for the enhancement of ultrafiltration and membrane cleaning by different ultrasonic frequencies, Desalination, 263 (2010) 133-138.

[6] D. Chen, L.K. Weavers, H.W. Walker, J.J. Lenhart, Ultrasonic control of ceramic membrane fouling caused by natural organic matter and silica particles, Journal of Membrane Science, 276 (2006) 135-144.

[7] I. Masselin, X. Chasseray, L. Durand-Bourlier, J.-M. Lainé, P.-Y. Syzaret, D. Lemordant, Effect of sonication on polymeric membranes, Journal of Membrane Science, 181 (2001) 213-220. 
[8] X. Chai, T. Kobayashi, N. Fujii, Ultrasound effect on cross-flow filtration of polyacrylonitrile ultrafiltration membranes, Journal of Membrane Science, 148 (1998) 129-135.

[9] X. Li, J. Yu, A.G.A. Nnanna, Fouling mitigation for hollow-fiber UF membrane by sonication, Desalination, 281 (2011) 23-29.

[10] A. Simon, N. Gondrexon, S. Taha, J. Cabon, G. Dorange, Low-Frequency Ultrasound to Improve Dead-End Ultrafiltration Performance, Separation Science and Technology, 35 (2000) 2619-2637.

[11] K.K. Latt, T. Kobayashi, Ultrasound-membrane hybrid processes for enhancement of filtration properties, Ultrasonics Sonochemistry, 13 (2006) 321-328.

[12] T. Kobayashi, X. Chai, N. Fujii, Ultrasound enhanced cross-flow membrane filtration, Separation and Purification Technology, 17 (1999) 31-40.

[13] R.A. Al-Juboori, T. Yusaf, Biofouling in RO system: Mechanisms, monitoring and controlling, Desalination, 302 (2012) 1-23.

[14] A.L. Lim, R. Bai, Membrane fouling and cleaning in microfiltration of activated sludge wastewater, Journal of Membrane Science, 216 (2003) 279-290.

[15] S. Popović, M. Djurić, S. Milanović, M.N. Tekić, N. Lukić, Application of an ultrasound field in chemical cleaning of ceramic tubular membrane fouled with whey proteins, Journal of Food Engineering, 101 (2010) 296-302.

[16] M.O. Lamminen, H.W. Walker, L.K. Weavers, Cleaning of particle-fouled membranes during crossflow filtration using an embedded ultrasonic transducer system, Journal of Membrane Science, 283 (2006) 225-232.

[17] M.O. Lamminen, H.W. Walker, L.K. Weavers, Effect of Fouling Conditions and Cake Layer Structure on the Ultrasonic Cleaning of Ceramic Membranes, Separation Science and Technology, 41 (2006) 3569-3584.

[18] M. Ashokkumar, J. Lee, B. Zisu, R. Bhaskarcharya, M. Palmer, S. Kentish, Sonication increases the heat stability of whey proteins, Journal of Dairy Science, 92 (2009) 5353-5356.

[19] S. Muthukumaran, S.E. Kentish, M. Ashokkumar, G.W. Stevens, Mechanisms for the ultrasonic enhancement of dairy whey ultrafiltration, Journal of Membrane Science, 258 (2005) 106-114.

[20] S. Muthukumaran, S.E. Kentish, G.W. Stevens, M. Ashokkumar, Application of ultrasound in membrane separation processes: a review, Reviews in Chemical Engineering, 22 (2006) 155-194.

[21] S. Muthukumaran, S.E. Kentish, G.W. Stevens, M. Ashokkumar, R. Mawson, The application of ultrasound to dairy ultrafiltration: The influence of operating conditions, Journal of Food Engineering, 81 (2007) 364-373.

[22] A. Mirzaie, T. Mohammadi, Effect of ultrasonic waves on flux enhancement in microfiltration of milk, Journal of Food Engineering, 108 (2012) 77-86.

[23] B. Zisu, R. Bhaskaracharya, S. Kentish, M. Ashokkumar, Ultrasonic processing of dairy systems in large scale reactors, Ultrasonics Sonochemistry, 17 (2010) 1075-1081.

[24] Q. Wang, A. Tolkach, U. Kulozik, Quantitative assessment of thermal denaturation of bovine $\alpha$ lactalbumin via low-intensity ultrasound, HPLC, and DSC, Journal of Agricultural and Food Chemistry, 54 (2006) 6501-6506.

[25] C.V. Morr, R.L. Richter, Chemistry of Processing, in: N.P. Wong, R. Jenness, M. Keeney, E.H. Marth (Eds.) Fundamentals of Dairy Chemistry, Aspen Publishers, New York, 1999, pp. 739-766.

[26] E.F. Deysher, B.H. Webb, G.E. Holm, The relations of temperature and time of forewarming of milk to the heat stability of its evaporated product, Journal of Dairy Science, 7 (1929) 80-89.

[27] H. Singh, Heat stability of milk, International Journal of Dairy Technology, 57 (2004) 111-119.

[28] B.H. Webb, R.W. Bell, The effect of high-temperature short-time forewarming of milk upon the heat stability of its evaporated product, Journal of Dairy Science, 25 (1942) 301-311.

[29] A. Tolkach, U. Kulozik, Reaction kinetic pathway of reversible and irreversible thermal denaturation of $\beta$-lactoglobulin, Lait, 87 (2007) 301-315.

[30] J. Chandrapala, B. Zisu, M. Palmer, S. Kentish, M. Ashokkumar, Effects of ultrasound on the thermal and structural characteristics of proteins in reconstituted whey protein concentrate, Ultrasonics Sonochemistry, 18 (2011) 951-957. 
[31] C.-C. Ho, A.L. Zydney, A combined pore blockage and cake filtration model for protein fouling during microfiltration, Journal of Colloid and Interface Science, 232 (2000) 389-399.

[32] L. Palacio, C.-C. Ho, A.L. Zydney, Application of a pore-blockage-Cake-filtration model to protein fouling during microfiltration, Biotechnology and Bioengineering, 79 (2002) 260-270.

[33] L. Palacio, C.C. Ho, P. Prádanos, A. Hernández, A.L. Zydney, Fouling with protein mixtures in microfiltration: BSA-lysozyme and BSA-pepsin, Journal of Membrane Science, 222 (2003) 41-51.

[34] M. Cheryan, Ultrafiltration and Microfiltration Handbook, Technomic Publishing Company, Lancaster, 1998.

[35] T. Kimura, T. Sakamoto, J.-M. Leveque, H. Sohmiya, M. Fujita, S. Ikeda, T. Ando, Standardization of ultrasonic power for sonochemical reaction, Ultrasonics Sonochemistry, 3 (1996) S157-S161.

[36] R.F. Contamine, A.M. Wilhelm, J. Berlan, H. Delmas, Power measurement in sonochemistry, Ultrasonics Sonochemistry, 2 (1995) S43-S47.

[37] B. Zisu, J. Lee, J. Chandrapala, R. Bhaskaracharya, M. Palmer, S. Kentish, M. Ashokkumar, Effect of ultrasound on the physical and functional properties of reconstituted whey protein powders, Journal of Dairy Research, 78 (2011) 226-232.

[38] H.C. van de Hulst, Light Scattering by Small Particles, John Wiley and Sons, New York, 1957.

[39] A. Kato, Y. Osako, N. Matsudomi, K. Kobayashi, Changes in the emulsifying and foaming properties of proteins during heat denaturation, Agricultural Biological Chemistry, 47 (1983) 33-37.

[40] S. Mleko, Gelation of shear treated whey protein polymers/aggregates, Journal of Food Science and Technology, 39 (2002) 167-169.

[41] C. Sanchez, M. Pouliot, S.F. Gauthier, P. Paquin, Thermal aggregation of whey protein isolate containing microparticulated or hydrolyzed whey proteins, Journal of Agricultural and Food Chemistry, 45 (1997) 2384-2392.

[42] P. Havea, H. Singh, L.K. Creamer, O.H. Campanella, Electrophoretic characterization of the protein products formed during heat treatment of whey protein concentrate solutions, Journal of Dairy Research, 65 (1998) 79-91.

[43] S. Iametti, S. Cairoli, B. De Gregori, F. Bonomi, Modifications of High-Order Structures upon Heating of .beta.-Lactoglobulin: Dependence on the Protein Concentration, Journal of Agricultural and Food Chemistry, 43 (1995) 53-58.

[44] U.M. Elofsson, P. Dejmek, M.A. Paulsson, Heat-induced aggregation of $\beta$-lactoglobulin studied by dynamic light scattering, International Dairy Journal, 6 (1996) 343-357.

[45] X.L. Qi, S. Brownlow, C. Holt, P. Sellers, Thermal denaturation of $\beta$-lactoglobulin: effect of protein concentration at pH 6.75 and 8.05, Biochimica et Biophysica Acta (BBA) - Protein Structure and Molecular Enzymology, 1248 (1995) 43-49.

[46] M.A. de la Fuente, H. Singh, Y. Hemar, Recent advances in the characterisation of heat-induced aggregates and intermediates of whey proteins, Trends in Food Science \& Technology, 13 (2002) 262274.

[47] S. Muthukumaran, Ultrasonic Enhancement of Dairy Ultrafiltration Membrane Processes, in: Department of Chemical and Biomolecular Engineering and School of Chemistry, The University of Melbourne, Australia, 2005.

[48] N.D. Lawrence, J.M. Perera, M. Iyer, M.W. Hickey, G.W. Stevens, The use of streaming potential measurements to study the fouling and cleaning of ultrafiltration membranes, Separation and Purification Technology, 48 (2006) 106-112.

[49] J.F. Hayes, J.A. Dunkerley, L.L. Muller, A.T. Griffin, Studies on whey processing by ultrafiltration II. Improving permeation rates by preventing fouling, Australian Journal of Dairy Technology, 29 (1974) 132-140. 


\section{List of Tables}

Table 1: Summary of volume-weighted average particle size, $\mathrm{D}[4,3](\mu \mathrm{m})$ of native, preheated (PreH), sonicated (US) and post heated (PostH) WPC80 solutions.

Table 2: Viscosity (cP) at a shear rate of $200 \mathrm{~s}^{-1}$ of native, preheated (PreH), sonicated (US) and post heated (PostH) WPC80 solutions.

Table 3: The steady state permeate flux $\left(\mathrm{L} / \mathrm{m}^{2} . \mathrm{h}\right)$ after $4 \mathrm{~h}$ of native, preheated $(\mathrm{PreH})$, sonicated (US) and post heated (PostH) WPC80 feeds.

Table 4: Comparison of the permeate flux during a water flush and after chemical cleaning, normalised to the initial pure water flux at the start of a filtration run.

Table 5: Best fit values of the fouling parameters for native and sonicated fresh whey feeds. 


\begin{tabular}{cccccc}
\hline $\begin{array}{c}\text { Feed } \\
\begin{array}{c}\text { Concentration } \\
\text { (wt\%) }\end{array}\end{array}$ & Native & Sonicated & PreH & PreH+US & $\begin{array}{c}\text { PreH+US } \\
\text { +PostH }\end{array}$ \\
\hline $\mathbf{5}$ & $24.7 \pm 0.1$ & $0.19 \pm$ & $35.0 \pm 1.6$ & $1.5 \pm 0.2$ & $1.6 \pm 0.1$ \\
10 & $37.5 \pm 0.7$ & $1.1 \pm 0.6$ & $48.1 \pm 1.6$ & $5.3 \pm 0.1$ & $6.0 \pm 0.1$ \\
$\mathbf{1 2}$ & & & $56.6 \pm 1.8$ & $12.5 \pm 0.1$ & $13.0 \pm 1.4$ \\
$\mathbf{1 5}$ & & & $77.9 \pm 2.9$ & $32.1 \pm 0.8$ & $32.7 \pm 0.2$ \\
\hline
\end{tabular}

Table 1

\begin{tabular}{cccccc}
\hline $\begin{array}{c}\text { Feed } \\
\begin{array}{c}\text { Concentration } \\
\text { (wt\%) }\end{array}\end{array}$ & Native & Sonicated & PreH & PreH+US & $\begin{array}{c}\text { PreH+US } \\
\text { +PostH }\end{array}$ \\
\hline $\mathbf{5}$ & $3.2 \pm 0.1$ & $3.0 \pm 0.1$ & $10.0 \pm 1.3$ & $3.0 \pm 0.1$ & $3.0 \pm 0.1$ \\
$\mathbf{1 0}$ & $4.5 \pm 0.1$ & $4.1 \pm 0.1$ & $61.6 \pm 0.7$ & $7.7 \pm 0.1$ & $7.2 \pm 1.7$ \\
$\mathbf{1 2}$ & & & $134 \pm 0.1$ & $9.0 \pm 0.0001$ & $9.5 \pm 0.1$ \\
$\mathbf{1 5}$ & & & $202 \pm 0.1$ & $10.9 \pm 0.001$ & $11.8 \pm 1.7$ \\
\hline
\end{tabular}

Table 2 


\begin{tabular}{ccccc}
\hline $\begin{array}{c}\text { Feed } \\
\begin{array}{c}\text { Concentration } \\
\text { (wt\%) }\end{array}\end{array}$ & Native & Sonicated & PreH & PreH+US \\
\hline $\mathbf{5}$ & $23.6 \pm 0.4$ & $23.7 \pm 0.6$ & $13.0 \pm 0.9$ & $15.6 \pm 0.3$ \\
$\mathbf{1 0}$ & $16.8 \pm 0.3$ & $17.7 \pm 0.5$ & $8.0 \pm 0.7$ & $12.1 \pm 0.3$ \\
$\mathbf{1 2}$ & & & $4.9 \pm 0.3$ & $7.7 \pm 0.5$ \\
$\mathbf{1 5}$ & & & $2.6 \pm 0.2$ & $5.7 \pm 0.6$ \\
\hline
\end{tabular}

Table 3

\begin{tabular}{lcc}
\hline \multicolumn{1}{c}{ Feed } & $\begin{array}{c}\text { Flux recovery } \\
\text { during } \\
\text { water flush } \\
(\%)\end{array}$ & $\begin{array}{c}\text { Flux recovery } \\
\text { after } \\
\text { cleaning (\%) }\end{array}$ \\
\hline $\mathbf{5}$ wt\% Native & 43 & 100 \\
$\mathbf{5}$ wt\% US & 44 & 103 \\
$\mathbf{5}$ wt\% PreH & 26 & 76 \\
$\mathbf{5}$ wt\% PreH+US & 32 & 87 \\
\hline
\end{tabular}

Table 4

\begin{tabular}{lcc}
\hline & Native & Sonicated \\
\hline$\alpha\left(\mathrm{m}^{2} / \mathrm{kg}\right)$ & $2.01 \pm 0.05$ & $2.84 \pm 0.04$ \\
$R_{p o}\left(\times 10^{12} \mathrm{~m}^{-1}\right)$ & $1.58 \pm 0.03$ & $1.40 \pm 0.01$ \\
$f^{\prime} R^{\prime}\left(\times 10^{11} \mathrm{~m} / \mathrm{kg}\right)$ & $3.73 \pm 0.07$ & $2.95 \pm 0.03$ \\
\hline
\end{tabular}

Table 5 


\section{List of Figures}

Figure 1: Schematic diagram showing the arrangement for sonication of the whey solutions.

Figure 2: Schematic diagram showing the arrangement of the ultrafiltration rig with $0.014 \mathrm{~m}^{2}$ membrane area.

Figure 3: Confocal laser scanning microsopy (CLSM) images of (a) native, (b) US, (c) PreH, (d) PreH+US and (e) PreH+US + PostH 5 wt\% WPC80 stained with a protein dye, FCF fast green. In all cases, the white scale bar indicates $10 \mu \mathrm{m}$.

Figure 4: Particle size distribution of native, US, PreH, PreH+US and PreH+US+PostH 5 wt\% WPC80 solutions.

Figure 5: Flux decline analysis for 5 and 10 wt\% native and US WPC80 feeds for the combined pore blockage and cake filtration model. Symbols represent experimental data for $5 \mathrm{wt} \%$ native (४) , $5 \mathrm{wt} \%$ US ( $\square$, $10 \mathrm{wt} \%$ native ( $\mathbf{\Lambda}$ ) and $10 \mathrm{wt} \%$ US (O) respectively, while solid curves are model calculations using Equations 3 and 4.

Figure 6: Comparison of the best-fit values of the fouling parameters, pore blockage parameter $(\alpha)$, initial resistance of the deposit $\left(r_{p o}\right)$ and cake growth factor ( $\left.f^{\prime} R^{\prime}\right)$ of native and sonicated (US) WPC80 feeds using the combined pore blockage and cake filtration model.

Figure 7: Best-fit values of the fouling parameters, pore blockage parameter $(\alpha)$, initial resistance of the deposit $\left(\mathrm{r}_{\mathrm{p} 0}\right)$ and cake growth factor (f'R') of PreH and PreH+US WPC80 feeds using Equations 3 and 4.

Figure 8: Plot of the steady state flux obtained for native, PreH and PreH+US WPC80 feed versus their respective protein concentrations. Experimental data are represented by symbols native, - PreH and $\square$ PreH+US) Solid lines represent results from best-fit values calculated using the gel polarisation model as shown by Equation 7 .

Figure 9 Permeate flux of fresh whey during $4 \mathrm{~h}$ of constant concentration UF. Symbols represent experimental data of native ( $\bullet$ and sonicated $(\square)$ feed respectively while solid curves are model calculations using Equations 3 and 4. 


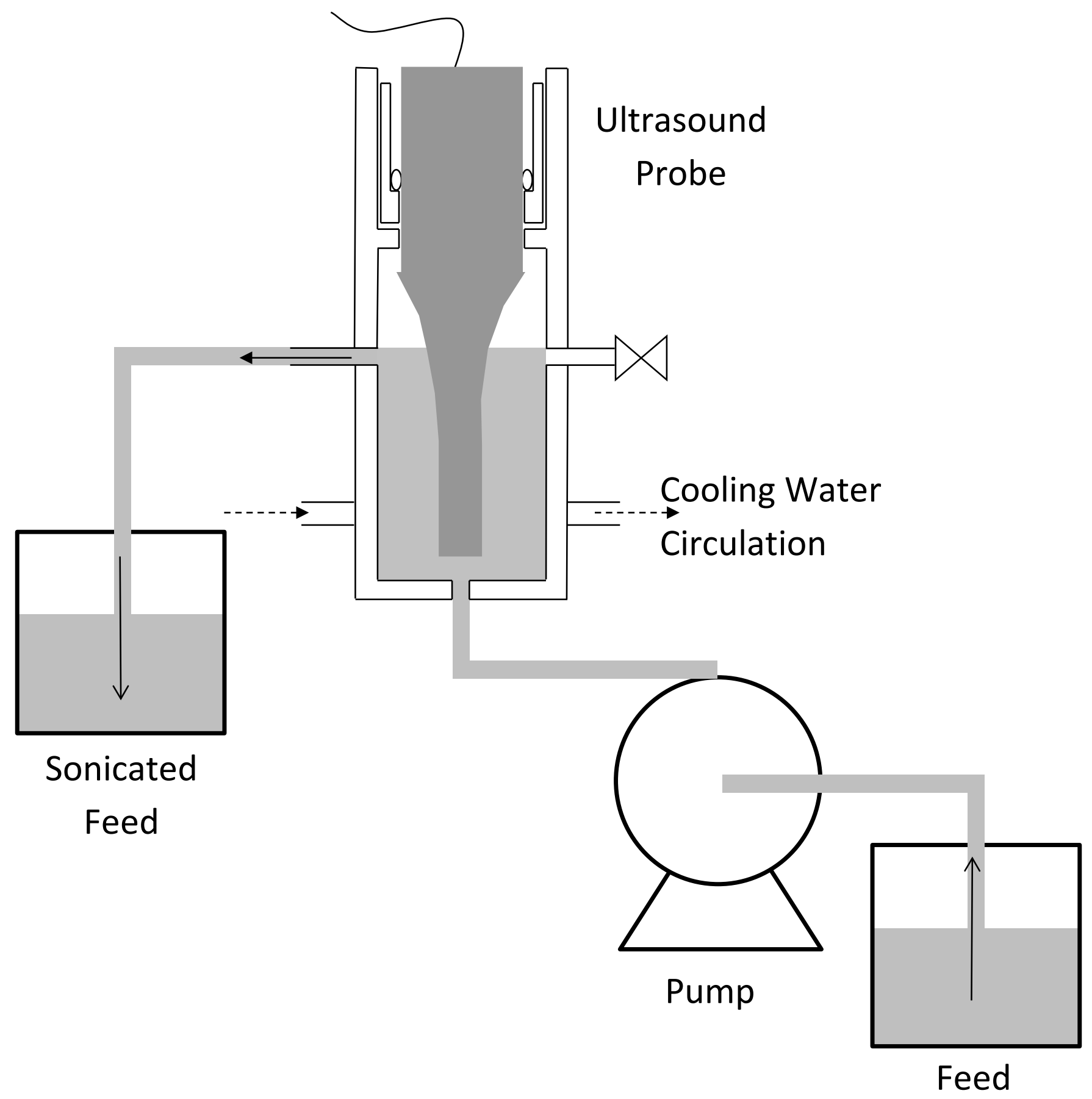




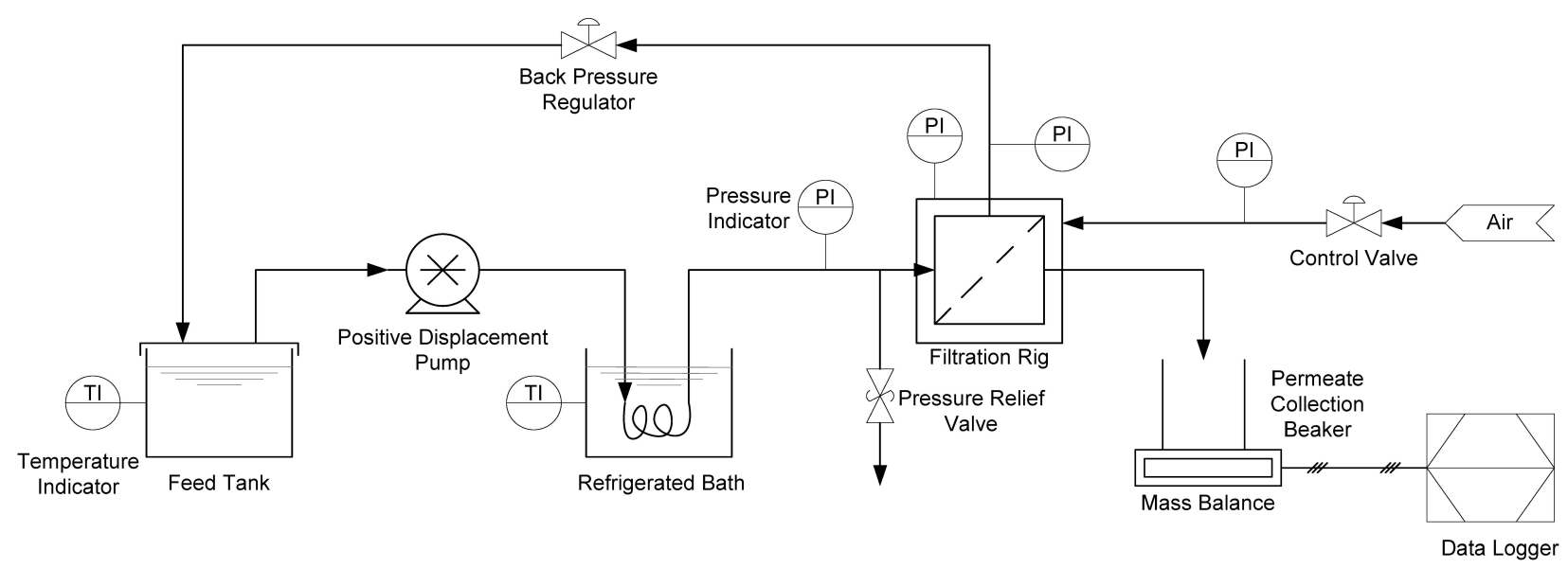


(a)

(b)

(c)

(d)

(e) 


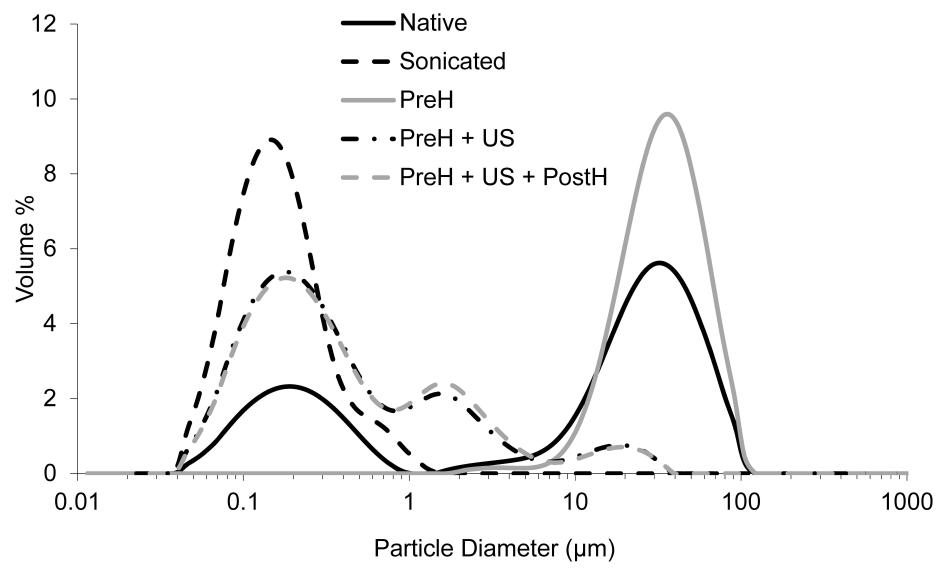




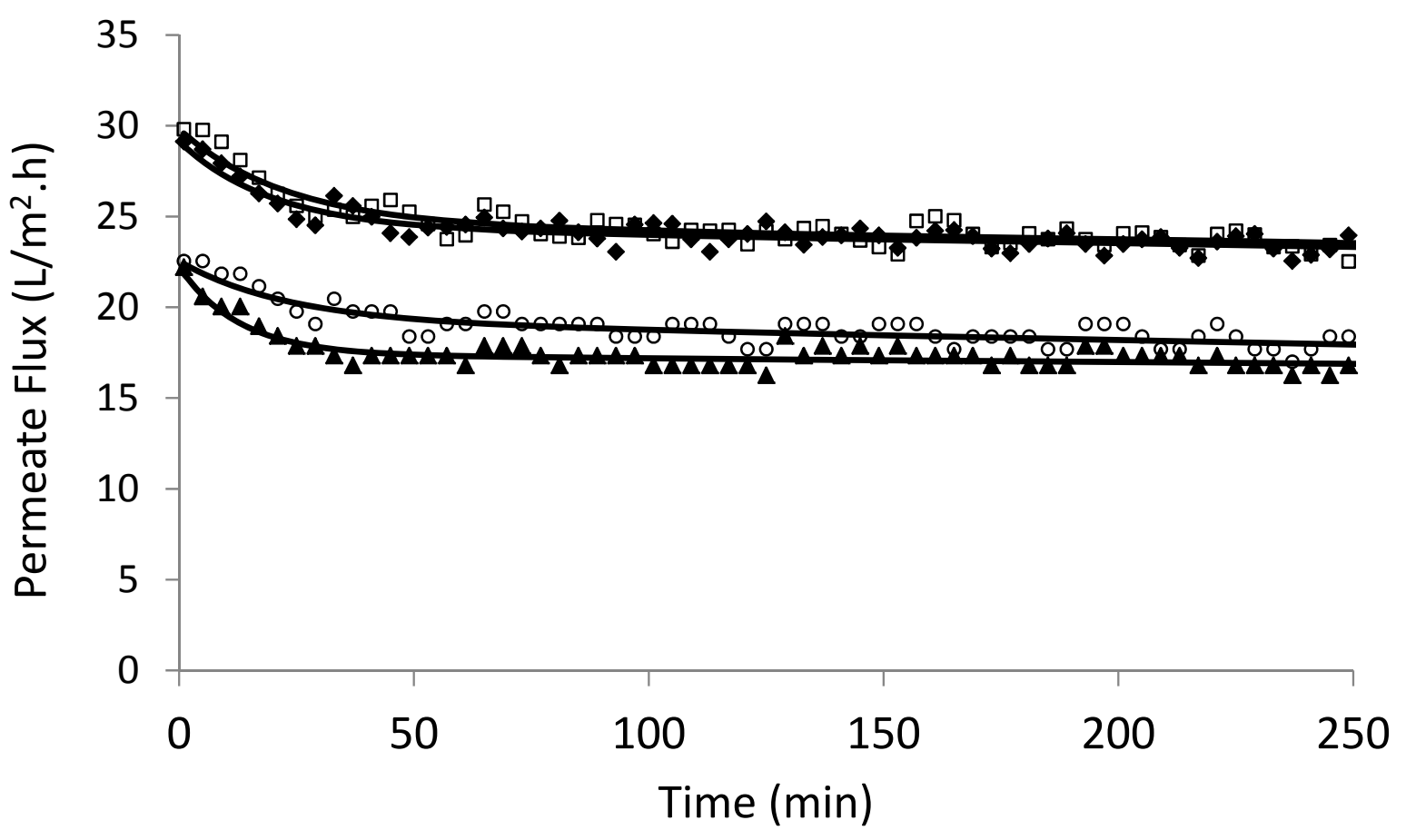




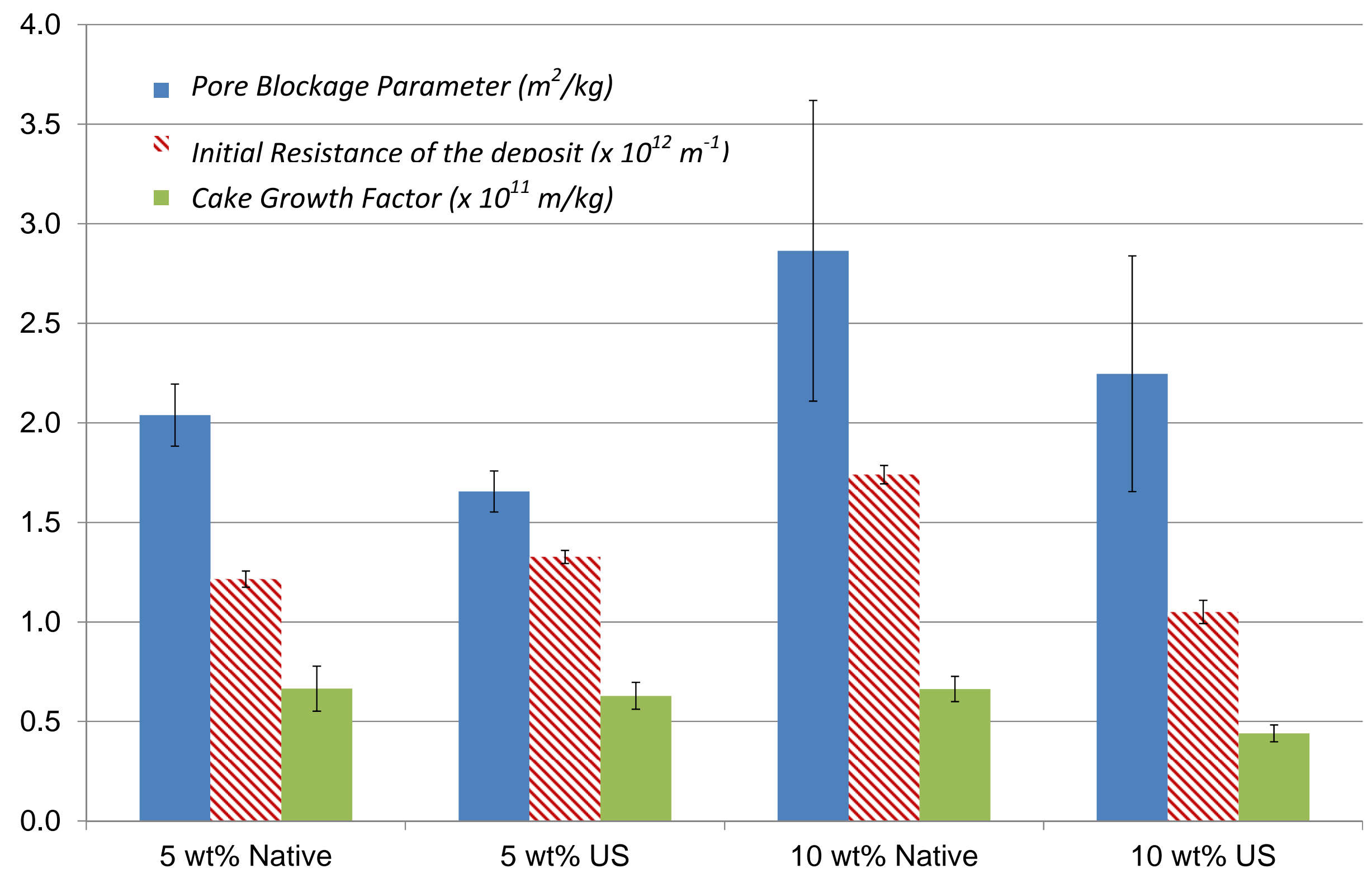




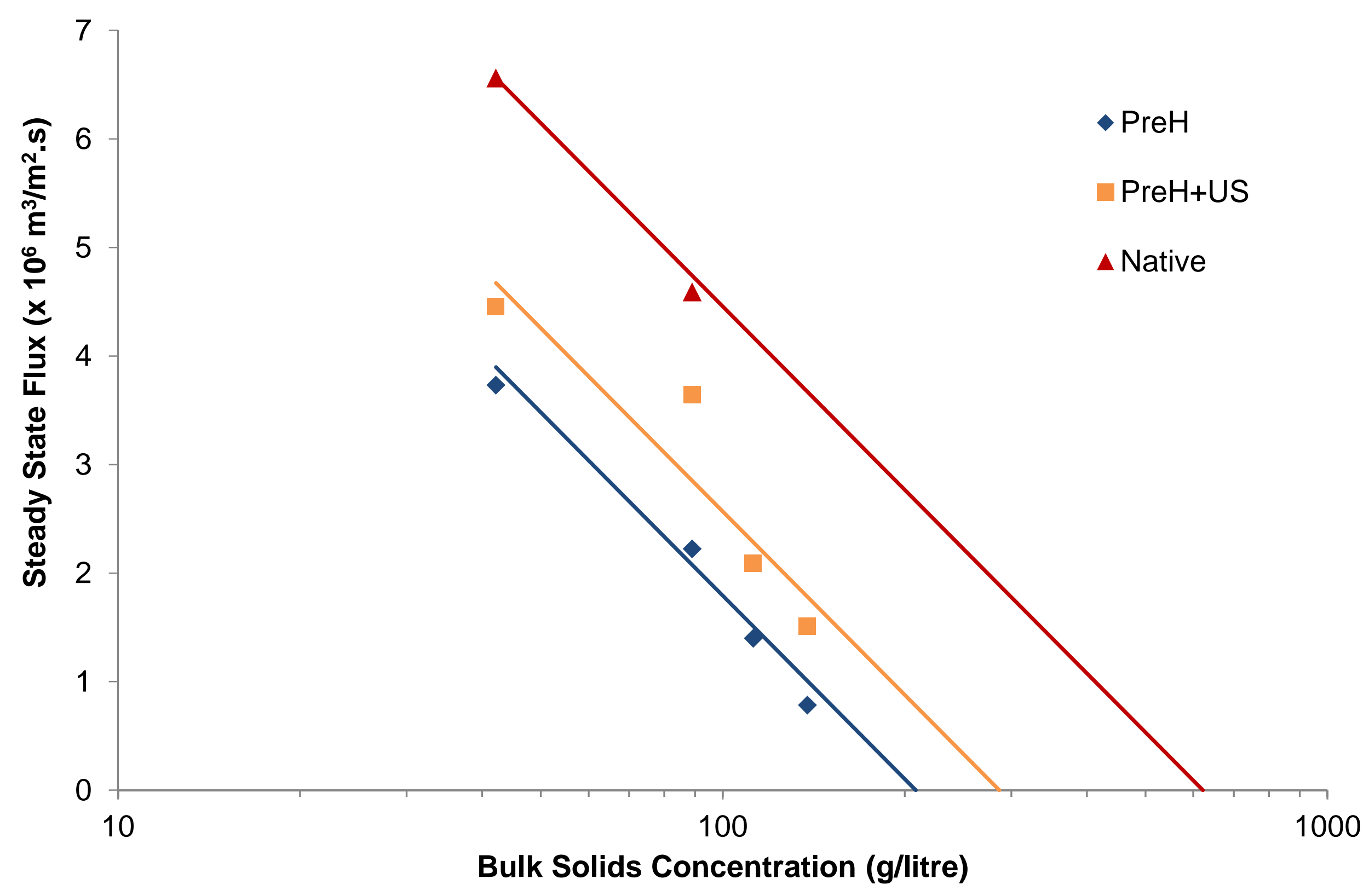




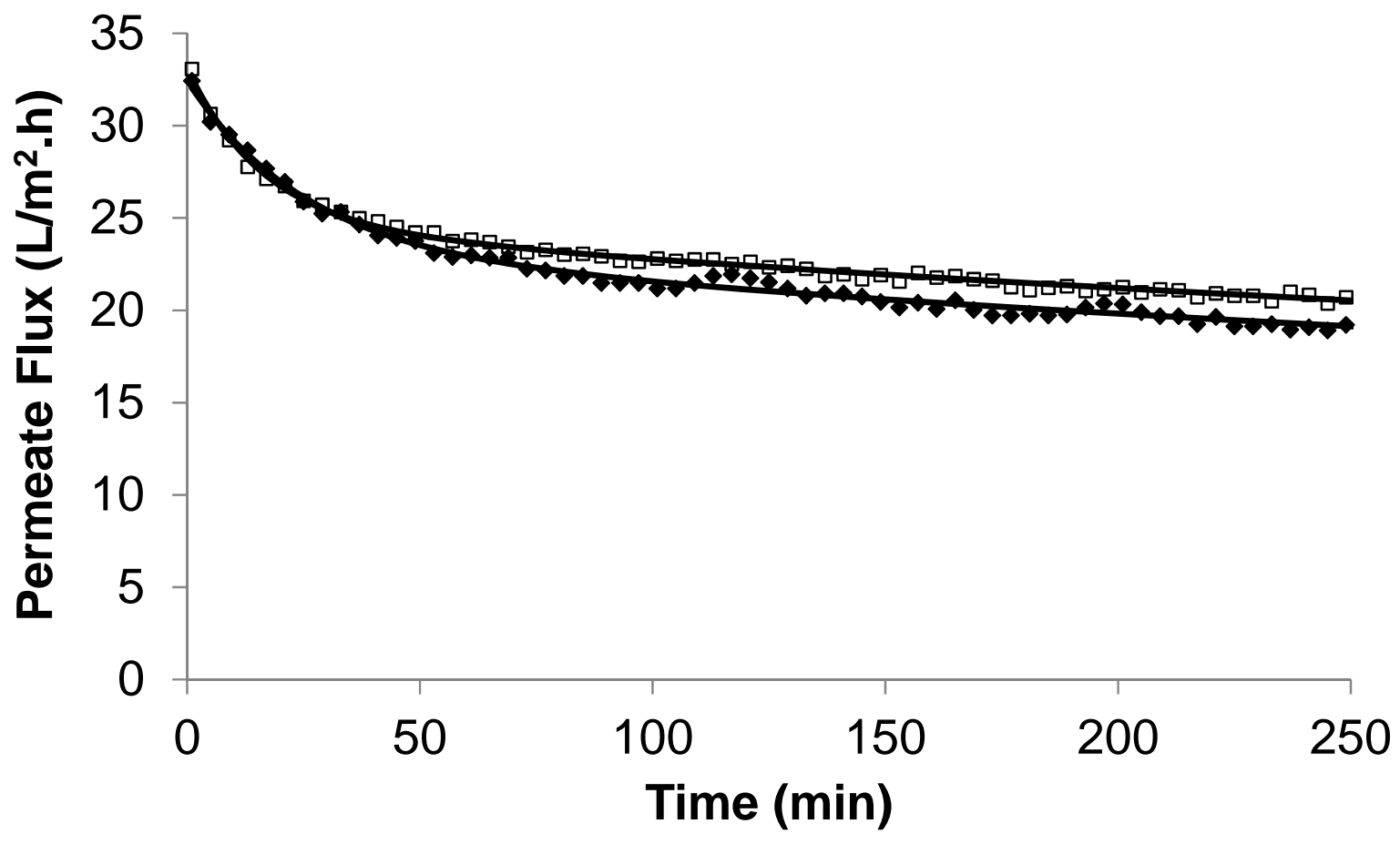




\section{University Library}

\section{- M M N E R VA A gateway to Melbourne's research publications}

Minerva Access is the Institutional Repository of The University of Melbourne

Author/s:

Koh, LLA;Hanh, THN;Chandrapala, J;Zisu, B;Ashokkumar, M;Kentish, SE

Title:

The use of ultrasonic feed pre-treatment to reduce membrane fouling in whey ultrafiltration

Date:

2014-03-01

Citation:

Koh, L. L. A., Hanh, T. H. N., Chandrapala, J., Zisu, B., Ashokkumar, M. \& Kentish, S. E. (2014). The use of ultrasonic feed pre-treatment to reduce membrane fouling in whey ultrafiltration. JOURNAL OF MEMBRANE SCIENCE, 453, pp.230-239. https:// doi.org/10.1016/j.memsci.2013.11.006.

Persistent Link:

http://hdl.handle.net/11343/55106 